\title{
(息)
}

Citation:

Norman, L (2014) A crisis of confidence: Women coaches' responses to their engagement in resistance. Sport, Education and Society, 19 (5). 532 - 551. ISSN 1357-3322 DOI: https://doi.org/10.1080/13573322.2012.689975

Link to Leeds Beckett Repository record:

https://eprints.leedsbeckett.ac.uk/id/eprint/1880/

Document Version:

Article (Accepted Version)

The aim of the Leeds Beckett Repository is to provide open access to our research, as required by funder policies and permitted by publishers and copyright law.

The Leeds Beckett repository holds a wide range of publications, each of which has been checked for copyright and the relevant embargo period has been applied by the Research Services team.

We operate on a standard take-down policy. If you are the author or publisher of an output and you would like it removed from the repository, please contact us and we will investigate on a case-by-case basis.

Each thesis in the repository has been cleared where necessary by the author for third party copyright. If you would like a thesis to be removed from the repository or believe there is an issue with copyright, please contact us on openaccess@leedsbeckett.ac.uk and we will investigate on a case-by-case basis. 


\section{A Crises' of Confidence: Women Coaches' Responses to their Engagement in Resistance}

\section{Author:}

Leanne Norman

Author's affiliation:

Carnegie Faculty

Leeds Metropolitan University

Headingley Campus

Headingley

Leeds

LS6 3QS

United Kingdom

Email: L.J.Norman@leedsmet.ac.uk 


\begin{abstract}
This study centres upon the accounts of master women coaches based in the UK, exploring how they have individually experienced such acts of resistance as reaching the top of such a male dominated profession. By going beyond previous positivist feminist approaches to this focus of inquiry, I employ a feminist cultural studies framework to understand how the social construction of what it means to be a woman impacts women coaches' individual sense of self and confidence to lead. The discussions are based upon semi-structured in-depth interviews with six senior national women coaches of team sports in the UK. The data highlights the success of masculine hegemony of coaching through documenting women's reluctance to advance their coaching career through a lack of self-belief and motivation as a consequence of their culturally and historically marginal position. The findings illustrate a pressing need for a revision of the dominant values inherent in professional sport in order to engage and retain potential women leaders.
\end{abstract}

Key words: • Women $\bullet$ Resistance $\bullet$ Coaching $\bullet$ Culture $\bullet$ Hegemony 


\section{Introduction}

The underrepresentation and status of women in coaching is a welldocumented and researched area (e.g. Acosta \& Carpenter, 2012; Cunningham \& Sagas, 2002; Cunningham \& Sagas, 2003a; Everhart \& Chelladurai, 1998; Kamphoff, Armentrout \& Driska, 2010; Kane \& Stangl, 1991; Kilty, 2006; Knoppers, 1994; Lowry \& Lovett, 1997; Norman, 2008; Parks et al, 1995; Pastore, Inglis \& Danylchuk, 1996; Theberge, 1993), highlighting the paradoxical global popularity of and participation in sport by women alongside the stagnation and even decline in the number of women in sports leadership. For example, the most recent report in the longitudinal research conducted by Acosta and Carpenter (2012) demonstrates that while the number of women coaches in U.S. collegiate sport has risen slightly since 2011, the number is still considerably lower than the inception of Title IX in 1972. At that time, $90 \%$ of women's teams were coached by women. This figure now stands at $42.9 \%$. The stagnation in the number of women coaches is evident even more so in the context of men's sport. The number of collegiate men's teams with a woman head coach remains near the same figure as it was in 1972 at approximately 3\% (Acosta \& Carpenter, 2012). In the UK, the current number of women coaches is similarly low. Over the course of two coach tracking studies conducted by Sports Coach UK, the statistics reveal an increase in the number of men in the profession, up to $69 \%$ in 2011 compared to 62\% in 2006 (Sports Coach UK, 2011). The picture is even bleaker when specifically focusing upon the number of men and women that are considered 'qualified' coaches and on the number of coaches at a high performance level (i.e. at the 'top end' of the athletic pathway). For example, statistics reveal that $82 \%$ of qualified coaches, i.e. coaches that hold a qualification in the sport they coach, are men (Sports Coach, 2011) and at the time of conducting 
the research, within the national squads of team sports within the UK, only nine teams had a woman head coach compared to 43 male head coaches.

The research that has addressed women's under-representation in the coaching profession has often attempted to locate definitive reasons as to why there are so few and even decreasing numbers of professional women coaches. On closer examination of the majority of scholarship on the under-representation of women coaches, utilising Dewar's (1991) analysis of the research philosophies adopted in research on gender and sport, it is evident that there are two distinct and dominant ideological positions. One strand of research related to women in coaching is the empirical investigation and quantification of sex differences in relation to ability and behaviour, referred to as "categoric research" (Dewar, 1991, p.18). Examples of explanations forwarded as to the under-representation of women coaches include lower self-efficacy, less intention, desire and motivation to coach as well as higher intent to leave the profession in women compared to men coaches. The second prominent ideological position that dominates the literature related to women's absence in coaching is "distributive research" (Dewar, 1991, p. 18). Within such frameworks, investigations take place into 'technical' issues and barriers, such as opportunities to coach, in the pursuit of equality for all individuals on the assumption that sport and coaching systems are meritocratic (Bryant \& McElroy, 1997). Within such liberal perspectives on gender and sport, power is conceptualised as belonging to individuals who have it rather than the assumption of an underpinning system of power relations (Halford \& Leonard, 2001). Women's unequal position in coaching is perceived as a pattern of discrimination as a reflection of, what Halford and Leonard (2001, p. 28) describe as, "multiple individual exercises of discrimination...rather than a coordinated conspiracy". Within this article, I explore the previous categoric 
and distributive research to understand their explanations for women's position within coaching. The central research questions that framed the present study were: (i) how have national women coaches experienced reaching the most senior levels of coaching? (ii) how does the culture of sport and coaching impact women coaches' sense of self? From an exploration of previous literature, this leads me into offering an alternative view for this research field, explaining the methodology adopted for the research. Finally, I present the accounts of the participants, who through their narratives demonstrate the deep, underlying complexities that lie at the heart of women's experiences as coaches.

\section{Previous explanations for the Underrepresentation of Women in Coaching}

Previous studies that have investigated women's under-representation in sport have provided a variety of reasons to explain this dearth of women. However there are still no clear answers to account for women's under-representation at all levels of the sports structure (Donohoe, 2004). The majority of researchers have concentrated their efforts upon categoric and distributive types of research, investigating possible explanations such as women's intention or motivation to become coaches, or prejudiced athlete preferences and expectations towards women as coaches. Distributive research has focused upon structural and organisational influences. In the following section, I examine such previous explanations to analyse and evaluate the factors that influence or explanations that seek to account for the under-representation of women in coaching.

Categoric explanations for understanding women's position within sports coaching have addressed possible differences in ability and behaviour in comparison to men, who dominate the profession. Much work has concluded that women do not 
possess the motivation and desire to progress through the coaching ranks, that women have higher intent to leave the profession than men or athletes prefer men to women coaches based upon predetermined evaluations of their coaching abilities, For example, Cunningham, Sagas and Ashley (2003) concluded that male coaches possessed greater coaching efficacy and desire to progress than women. Simultaneously, women coaches had greater intentions to leave the profession (Cunningham, Sagas \& Ashley, 2003). Their conclusion was that women coaches' lack of motivation may account for their minority status. The authors had previously argued that women have lower career aspirations and intention to remain in coaching (Cunningham \& Sagas, 2003b). Similarly, Stumph and Sagas (2005) reached a similar conclusion, adding that men coaches possessed greater human and social capital than their female counterparts. Everhart and Chelladurai (1998) also addressed women's underrepresentation as coaches as issue of preference and motivation to coach. Yet, within the conclusions of such research, the authors have often conceded that social conditions or some form of systematic discrimination may be an influence rather than individual traits. This was the conclusion of Lowry and Lovett's study (1997) into whether women leave coaching because of individual traits or the social context. Other categoric research has investigated whether the perceptions of athletes as to the abilities of women compared to men coaches, may explain women's underrepresentation. Any unfavourable attitudes may discourage women coaches from entering or continuing in the profession (Hasbrook, Hart, \& Mathes et al, 1990). Parkhouse and Williams (1986) sought to examine whether there is gender bias in an athlete's evaluation of coaches. Overall, it was found that male and female athletes always rated the man coach as the same or more favourably than the woman coach (Parkhouse \& Williams, 1986). Yet, Parkhouse 
and Williams (1986) do not consider or explore as to why the athletes perceived the male coaches and did not locate their study in the wider cultural context of sport. More recently, Manley et al (2010) also found that athletes rated the perceived competencies of male coaches more favourably than women.

As mentioned in the introduction, an alternative ideological perspective that also dominates the literature focusing upon the paucity of women in coaching is distributive research. Within this approach, the focus of inquiry is on 'technical' or practical issues, such as the availability of opportunities for women to coach, resources available for women to coach, recruitment patterns of coaches. Such issues are considered on the basis that sport is a meritocracy and that once such technicalities have been resolved, women will achieve 'equality' to men. From this perspective, equality is defined as having a greater number of women in the coaching profession. For example, Knoppers (1994) argues that opportunity to coach remains one of the most significant structural barriers and that this can account for why women drop out of coaching or fail to progress. Borrowing from Kanter's (1977) theory of structural influences to explain gender differences in work behaviours, Knoppers (1994) argues that opportunity is related to gender and so career ladders of men and women coaches are different. Men have more opportunity to progress and to occupy coaching positions of men and women teams (Knoppers, 1994). Knoppers (1994) also explains that the underrepresentation of women in coaching is a consequence of women possessing less capacity to mobilise their available resources. Those with such power have self-autonomy, individual alliances, freedom and access to resources in order to reach the top of their coaching career. In coaching, men dominate the positions of power and the implication of this is that women have no control or influence. Women subsequently leave the profession 
because they lack control of the direction of their coaching (Knoppers, 1994). This is in agreement with Mathes' conclusion (1982) who reported that women coaches do not progress in their career because of a lack of control.

Patterns of recruitment have also found to be linked to the deficit of women coaches (Lyle, 2002). Research has shown that coaching appointments are made as a result of informal invitations and assumed leadership (Lyle, 2002). The dominance of men in leadership and in positions of power may lead to more men being appointed (Lyle, 2002). Stangl and Kane (1991) and Lovett and Lowry (1994) have both found evidence that those in powerful positions for recruiting coaches, selected those similar to themselves. This contributed to the high numbers of women leaving the profession (Lovett \& Lowry, 1994). Kanter (1977) has described this as 'homologous reproduction' and this provided the basis of Cunningham and Sagas' (2003) study that found that those in powerful positions appoint similar individuals to themselves. This appears to still be the case, certainly in US collegiate sport, demonstrated by the recent published longitudinal survey by Acosta and Carpenter (2012). Their report showed that when an athletic director was a man, the percentage of women coaches appointed was lower than if the athletics director was a woman (Acosta \& Carpenter, 2012). Considering that approximately only one in five athletic directors are women (Acosta \& Carpenter, 2012), this may be a skewed pattern of recruitment that is set to continue for women coaches.

\section{The Need for an Alternative Theoretical Approach}

The major criticism of much of the existing research related to women's underrepresentation in coaching is the lack of socio-historical contextualisation to the research. Along with the simple acceptance of the governing values and practices 
within sport, many of the existing theories as to why there are so few women in the profession may have contributed to prevailing oppressive ideologies and preserved the status quo (Dewar, 1991; Mac an Ghaill \& Haywood, 2007). For example, within categoric and distributive arguments, there appears to be little engagement with the concept of power. Therefore, a crucial element missing to such research is a thorough and critical engagement with power, and how cultural relations as well as orders are created and contested. Instead, the liberal philosophy, underlying much of the women in coaching research, contends that power is only wielded by select individuals when conflict occurs (Bachrach \& Baratz, 1963). If women do not demonstrate any resistance or opposition it is because they are making a free choice to act in the manner they do and therefore, power has not been applied (Halford \& Leonard, 2001). In summary, this is tantamount to finger pointing and 'blaming' women for their underrepresentation or oppression as coaches. Such theoretical frameworks provide negligible understanding into how social practices such as sport are historically produced and culturally and socially defined as to create and maintain the hegemonic ideas of the dominant social groups (Hall, 1996). Consequently, such work has failed to challenge the hierarchical structure women experience in coaching (Hargreaves, 1993) and failed to move beyond inadequate and limited conceptualisations of power.

Alternatively, Hall (1996) argues that in a postmodern society, there is a need for theory that captures the significance of sport through an analysis of culture. Cultural studies provides this analysis and moves beyond paradigmatic boundaries to utilise different disciplines to subjectively study how cultural processes shape and in turn, are created by individuals through a struggle of power (Hall, 1996). Power in this instance is considered a "relational process, continuously in flux" rather than a 
calculation of resources or absolute whereby individuals have little possibility of changing their status (Brackenridge, 2001, p. 83). Rare research that has adopted such a paradigmatic approach to interrogate power in the highest echelons of UK sport includes Shaw and Slack's (2002) examination of gender relations and the culture of sporting organisations. The findings showed that language, policies and practices served to create an unequal order of gender relations which promoted masculinities (Shaw \& Slack, 2002). Similarly, the work of Fielding-Lloyd and Mean (2011) explored, using critical discourse analysis, the constructions of gender identities and women's underrepresentation as football coaches in England. Through unstructured interviews and observations of coach education courses, Fielding-Lloyd and Mean (2011) argued that women were consistently (re)produced as unconfident in their own skills and coaching abilities and thus framed as being responsible for their underrepresentation as coaches. This was in response to the potential challenge that women's presence in sport and coaching poses to a hegemonically masculine institution. In this way, it was constructed that women deserved to be outsiders in football coaching in a governing body that was perceived as forward thinking and liberal. The present study intends to add to this by similarly adopting a critical stance towards the culture of the coaching profession and the impact upon women coaches' experiences.

Consequently, this study addresses the gap in the existing coaching literature by drawing upon the strength of feminist cultural studies to understand the reactions of professional women coaches in the UK to their secondary status in both sport and society. I turn to Gramsci's theory of hegemony for its acknowledgement of human agency within historically created determinant social structures and Connell's (1987) application of this to power relations and gender to understand women's minority 
status as coaches (McDonald \& Birrell, 1999). Cultural leaderships and power is secured through the naturalisation and articulation of ruling ideas in popular cultures and the willing consent of those disenfranchised by such ideologies (Bennett, 2006). For the study of gender relations, it is the study of masculinity as hegemonic and the perspective that women constitute one of sport's subordinate social groups (Connell, 1987). A crucial component of the critical feminist project should be to qualitatively understand how hegemony affects those who live and experience sport everyday (Dewar, 1991). . In spite of the numerous studies that have focused on women's gross under-representation within the coaching profession, and much of it based in a North American context, there are still few studies that critique the culture of sport and coaching as being responsible for women's marginal status.

Critical feminist cultural studies have been facilitated to understand women's experiences as athletes but rarely for the case of women as coaches. Therefore, this study seeks to synthesise a critical approach into an area that has not been given the qualitative attention it deserves given the ideological repercussions of women's absence from roles of power. This is in order to produce a more complex, sophisticated awareness of how hegemony is challenged and obtained in the most senior levels of sports leadership (Birrell \& McDonald, 2000). Cultural studies perceive the struggle for dominance as a continual state of challenge and resistance, and therefore this approach can facilitate a more intricate conceptualisation of the struggle for cultural leadership (McDonald \& Birrell, 1999). The concept of resistance recognises structure and agency and that resistance can be a collective act as well as an individual act. For this paper, resistance is seen as women's occupation of the highest coaching positions of their sport and their individual attempts to empower other women around them to challenge the material and ideological constraints upon 
them (Shaw, 2001). This is based upon the premise that coaching is a form of political practice, implying that coaching behaviours, relations and contexts can be utilised to challenge the hegemony of current ideologies surrounding the coaching act and process (Shaw, 2001). Presenting women as elite coaches as a form of resistance requires us to understand coaching in a different way; it necessitates that we critique the coaching process and not accept it unquestionably as well as appreciating that women, through coaching, possess a position from which to challenge the oppressive ideologies and unequal power relations that rule sport. Specifically, I will examine the impact of the historically created and secured masculine hegemony of sport in the UK on professional women coaches' desire to overturn their marginal status within elite coaching.

\section{Methodology}

The relative absence of women from coaching is most significant at the most elite levels of the profession. With this in mind, I focused upon women who held senior head coaching roles in national team sports (both men and women's teams) based in the UK. These sports included football (soccer), field hockey, rugby league, rugby union, cricket, netball, basketball and volleyball. At the time of data collecting, nine women occupied such positions out of a possible 52. Therefore, purposive sampling was selected in order to interview women who were relevant to the research question (Bryman, 2004). This is not to say that the coaches were selected so as to support the research question, rather, they would answer it (Mason, 1996). A strategy of selecting participants based upon their coaching status, that is of national standard, protected against a common criticism of purposive sampling, that of being "ad hoc and vague" (Mason, 1996, p. 95). This strategy was also based upon the feminist cultural studies assertion that it is the most senior levels of 
responsibility in which hegemonic masculinity is most prevalent (Rindfleish \& Sheridan, 2003).

Prior to the research, formal ethical approval was provided by the University's ethics committee and all research was carried out in accordance with the University's ethical guidelines. Informal letters of information were then initially emailed to the nine women coaches identified. Six women agreed to participate in the study and consequently were sent formal letters detailing the research study. Four participants represented two national team sports and each of the other two participants were head coaches within two other national team sports. My approach to this study sought to address the limits of categoric and distributive research through centralising the women's experiences and understanding their underrepresentation from the perspective women coaches themselves. In this way, my research was for women, rather than considering women solely as subjects within the research. I carried out my role of researcher within a frame of feminist research ethics as envisioned by Brabeck and Ting (2000) and as part of my feminist standpoint epistemological position. The criterion for such feminist research is "completeness, plausibility...understanding and responsiveness to...subjects' experiences" (Reinharz, 1983, p. 171). Therefore, I conducted the research process from the perspective that the participants' experiences were morally significant (Cole \& Coultrap-McQuin, 1992). In order to achieve a greater depth to our understanding of women's experiences and to centralise the participants' accounts of their experiences from the standpoint of the women themselves, I conducted semistructured interviews with the participants (Kasper, 1994). Interviews were conducted with all six women coaches at a time and location convenient to the participant (all of which were at the participants' offices or places of work). 
The overall content of the interview was based upon an interview schedule devised for the purpose of the research and focused on (1) the participants' background in and early experiences of coaching, (2) the obstacles and achievements the participants had experienced throughout their career, (3) the participants' experiences of gender relations in coaching, and (4) the participants' ideas, as a product of their coaching experience, as to why women are underrepresented in the profession and therefore suggestions for the development and empowerment of potential and aspiring national women coaches. Participants were also asked to elaborate extra, relevant information that arose during the course of the interview. Each interview lasted between 60 and 120 minutes. All interviews were taperecorded and analysed using the constant comparison method of data coding (Glaser \& Strauss, 1967). This involved unitizing each interview transcript into smaller units of meaning and the response to each interview question comprised a unit. Each unit of meaning identified in the preparation stage was then compared to other units of meaning, such as when a particular participant described seeing women coaches reluctant to progress into senior coaching roles, and was then grouped with similar units to form a category such as 'women coaches lack selfconfidence'. When a unit of meaning could not be grouped with another, it formed a new category. Rules of inclusion for each category were written and connected to similar categories to show relationships and patterns across the data. As a further implication of the feminist research ethics employed for the research, I also sought to gain the trustworthiness and respect of the participants. To achieve this, I utilised the technique of respondent validation of the interview transcripts through providing each of the six women coaches with a transcribed account of our interview. Such a technique is popular with feminist researchers who seek to ensure that their study is 
respectful towards and appreciative of the participants' experiences (Olesen, 2000) and as an effective method of maintaining that the findings correspond with the experiences and perspectives of the participants (Bryman, 2004). On receipt and examination of our interview transcripts, none of the participants requested any changes to be made. Moreover, in further keeping with my ethical feminist research stance, I recognised my potential powerful position of the researcher as the author of the study (Olesen, 2000). Thus, I sought to equalise the researcher-researched relationship by maintaining the interviews as a consensual, collaborative process (Kasper, 1994) and considering each participant as the authority on their experiences. I also made explicit my feminist perspective, the aims of the study, and the theoretical perspective of the research.

A further element of Brabeck and Ting's (2000) vision of feminist research ethics is that the researcher(s) invest their effort into highlighting moral issues through remaining attentive to women's experiences. Feminists must be wary as to how they attend to and present women's experiences (Frye, 1983). Thus, rather than advocate these women's lives as one 'true reality' (Stanley \& Wise, 1993), this study is just one attempt to represent the participants' individual versions and constructions of their experiences within the UK coaching system. To protect identities given the small number pool of national women coaches from which the participants were drawn, I have assigned pseudonyms to each of the coaches in my following presentation of the results of the study

\section{Findings}

Two interlinked categories were derived as a result of the data analysis that framed women's feelings surrounding their progression to high performance coaching. In this section I present these themes as an illustration of the restrictive 
nature of the coaching culture on women coaches' sense of self and motivation to advance through their profession. Firstly, I highlight the effect of the norms and values within sport upon women's self confidence. Secondly, I present the accounts of the participants that highlight how the cultural expectations of women in sport impacts women's progression through coaching and how the male dominated culture of sport suffocates women's desire to coach.

\section{Self-identity: Confidence and Conflict}

The agreement between the national women coaches was that many aspiring and developing women coaches cannot challenge the patriarchal control of coaching and sports leadership because they do not believe in themselves as leaders. Within the theory of hegemony, oppressed social groups have the potential agency to challenge and reform their marginalised position. However, without the sense of will and action to overcome such oppression, any such contestation and subsequent reversal of fortune is unlikely. In the case of women breaking into powerful, culturally visible roles and opposing the dominant masculine hegemony of coaching, it appears that women are some distance from attempting to climb the career ladder. In the following interview excerpt one participant discusses her attempts to encourage assistant club level and national women coaches to step forward for senior roles. At the time of the interview, Anne, who was not British, was head coach of an England team in a sport that has a high population of women in leadership positions. She had come through what she believed was an extremely supportive coaching structure in her native country, after a playing career in which she was recognised as one of the most finest players of her sport that accumulated in her inclusion in her country's sporting hall of fame: 
The coaches here, I don't know about other sports, they lack an awful lot of confidence to step out and have a go... They're very reluctant to do it but I think a little bit of that is to do with a lack of self-confidence in themselves and their ability to coach, they don't want to step forwards because they don't want to embarrass themselves or they know they're not ready to take on that level.

The consequence for this participant is she is finding it extremely difficult to locate and mentor the next future national coach because so many women do not have the self-assurance to apply for such roles. There are fewer opportunities for women to coach because of the secondary status women's sport has compared to men's (Norman, 2008). But even if these occasions did arise, Anne debates as to whether women would want to put themselves forward for these chances:

It's really disappointing. It's about making [developing women coaches] feel worthwhile, making] them feel good enough. It's passing on to them they are good enough; they've got a lot to give. A lot of them, I find their self-esteem is very low as a coach... The more confident they're going to become and more self-belief that they're good enough [then] they [will] start eventually putting their hands up for the really top positions. But it will take time.

Another coach of the same sport, in which women dominate many of the coaching and leadership positions, found that getting women to feel confident in their ability to move from playing to coaching to elite coaching was difficult. In this quote, Helen, who has been involved in high performance coaching for at least ten years, 
describes her surprise that her assistant women coaches do not want to become head coach:

I can think of a couple of players of mine who would make fantastic coaches and I have been astounded when they've turned around and said "no I am not good enough, I'm not able enough to do it".

In regards as to why the participants have witnessed developing women coaches fail to believe in their ability to lead, one participant was very strong in her assertion that, in her sport, it is because women are aware of evaluation and hostility from male peers. Claire has reached the top of the coaching ladder in the women's game of her sport having been one of the most celebrated women players in her sport in terms of international and club level appearances. However, she too has experienced the hostility of fellow male coaches when she was undertaking her coaching qualifications and that only through a strong sense of self-confidence has she ignored this to achieve her coaching aspirations:

For me, I was very driven in terms of [my sport] and coaching. I think the problem and I know this for a fact because I've tried to address it, [women coaches] feel intimidated by male coaches. I had an arrogant belief that it wasn't a problem that I could probably play better than most of these guys. They can't tell me anything, that's how I thought and that's what got me through it. Whereas, a lot of women are cautious about that environment like, "I'm not a great player, they're [men] going to look at me in a different way"... because you know men are very judgemental towards women coaches because they assume, as males, they know more than women. It's quite intimidating for women, with a group 
of men who think they know more than you. I think it's stopped a lot of women progressing.

These excerpts from the interviews with the participants demonstrate that one of the first steps in enabling women to contest their under-representation is to increase their sense of self-worth and their perceptions of their own ability, both as previous athletes and as potential coaches. This means challenging the belief that often the 'best' players make the 'best' coaches. Through the ideologies that position men's sporting abilities as superior in comparison to women's will mean that women's coaching competencies are then unfavourably judged and underappreciated by athletes, administrators and other coaches. It appears from the remarks from the participants that these feelings of lack of self-efficacy to coach are significantly hampering their development as coaches and preventing them from following a career into senior coaching. Nevertheless, the participants themselves did not share a similar deficit in self-confidence. As women who have all reached the top of their professions, they all described a deep-rooted sense of self-assurance despite experiencing some social 'frowning'. Some credited this to early and sustained involvement in sport as well as a passion for the sport they play. Certainly, this was the case for Ruth who, like Claire, grounded her self-confidence in her awareness that she was a good player in her sport after playing at the highest tier of her native country's women domestic league. She is now national coach of a UK team in a sport traditionally dominated by men as both players and leaders:

Since I've been young, I've been a sportswoman and I don't think anyone has seen me as anything else. When I grew up, I didn't have any problems because I was quite strong [I didn't feel 
any bullying] because I think a large part of my identity as a person when I was young was that I was good at sports. My identity was fixed around that I was good at sport.

Claire's experiences are congruent with Ruth when Claire was faced with men who questioned her presence in a sport that is a flagship for masculinity in the UK:

It didn't faze me, didn't stop me playing, it didn't affect me in any shape or form. Maybe because I was a good player... The love of the game took over; I couldn't see anything else but the game. I grew up with a lot of boys on the estate and I thought I was little bit abnormal, the only girl who played... For me, because I was a good player, that's how I got through it. I suppose, I had an arrogant belief that it wasn't a problem that I could probably play better than most of these guys. They can't tell me anything, that's how I thought and that's what got me through it.

It was this confidence that drove Claire into coaching, and for some potential women coaches, the significance of such a visible woman in such a male dominated sport provided the motive for one of her players to begin coaching:

One of the national coaches... She played for the seniors then I mentored her if you like, but she point blank refused to coach. Then I changed her perceptions, her ideas and because I've progressed and she's seen that, [now] she's followed.

Often the negative responses to sportswomen stem from these women transgressing the cultural boundaries regarding the expectations for women in 
patriarchal society. This section has shown that the participants have witnessed less qualified women express great reluctance to pursue more elite coaching roles because they do not believe in themselves to be competent enough to lead in such a public role. The low self-confidence of women coaches' is demonstrated in these quotes. On the other hand, the participants attribute reaching the highest echelons and at times overcoming cultural disapproval through a deep sense of selfconfidence in their own ability as sportswomen. This does not mean, however, that women themselves are to blame for skewered gendered sports leadership. Instead it is important to analysis the impact of cultural constraints on women's behaviours and feelings (Birrell, 1988).

\section{Illusions of Triumph? Women's Coaching Experiences Shaped by Historical and Cultural Constraints}

Women coaches continue to be hampered by the cultural association of women with domesticity and childcare. Connell (1987) argues that society is assembled around a group of 'core' institutions and it is within the 'core institutions', such as governments and businesses, through which the legacy and maintenance of masculine hegemony is preserved. Messner (2002) proposes that with the significance of some contemporary sports in terms of both financial and as cultural activities, that sport could be considered as a core institution. Women continue to be primarily involved in peripheral institutions, such as the family, whilst still under patriarchal control (Connell, 1987). Such is the intricacy and complexity of historically gendered cultural expectations, that for women who want to become leaders in their sport "such firmly embedded expectations are difficult to overcome" (Miner, 1993, p. 44). Such expectations are detrimental to women building their sense of self-efficacy 
as coaches to contest for more senior roles, as Ruth has observed amongst women coaches in her sport:

I think that the social situation a woman has, the female coaches just don't have the self-confidence to go onto the next level. They haven't had anyone to give them self-confidence in coaching... They don't think they are good enough. When it comes to [my sport]... "You're just a woman and you're a man, so you know a lot more about [this sport]", that's how women see themselves and that's how men see themselves because it is their business.

It seems that the absence of women from the most powerful positions is not always that they are pushed out or kept down by the patriarchal strongholds of sport; women may actually self-select themselves out of the sports hierarchy as a response to selfdoubt and feelings of cultural inferiority. As one participant commented, many sporting organisations are worried about giving women coaches opportunities because they fear the 'floodgates' will open. But they need not be. As well as a deficit of self-confidence, many women do not have the desire to be an elite coach as Anne has observed in her sport:

I don't think it's a lot that want to step up to go higher. Not at the moment, there's just a couple of them and that's not many at all. You also find some of them don't particularly want to go [on coaching courses]; a lot of them don't want to coach at elite level they're very happy to sit down at club level. They don't want to progress beyond that, they don't want to get involved with being accredited and going to extra coach courses... [I guess] its nurturing them and slowly 
building their confidence to get them to move forwards [because] there's only usually a small handful of them.

As part of hegemonic ideology, power and autonomy are denied to those oppressed, in this case, women (Flax, 1995). Consequently, women may internalise feelings of low self worth and submission through the patriarchal devaluing of what women are culturally accepted to act, be and achieve (Flax, 1995). Therefore, women have often learnt the role of subordinate and as Ferguson (1995, p. 377) contends, this "role can easily become self-perpetuating", thus reinforcing their status.

With sport being an experience for the boys and domestic duties are 'for girls', such cultural activities have become gendered. Thus, the gender regime of sport is experienced as a cultural space that celebrates masculine styles of both play and leadership (Messner, 2002). Girls who grow up to be coaches feel disempowered and out of place. Fiona has been involved in high performance coaching for approximately five years in a sport that is considered in the UK as more 'gender equal' in terms of participation rates. She believes that it is the socialisation of boys from a young age in sport generates much more self-confidence in adulthood:

He'll [boys] think he could do it and try it. That's from when they grow up, somewhere along the line, the girls don't have the same desire or drive and get more fear and lose that "I can do it". That's why women will [remain in the lower levels of coaching].

For Claire, she perceives that progression through sport and coaching was a struggle because of a combination of her racial identity and the expectations of girls and women: 
I think initially, it was "ooh you play [sport]!" Back then... it was quite taboo women playing [my sport]... I think I had more conflict from my family initially because of West Indian culture, I had to go through that... So that was really the only conflict I had, cultural. It was like [the] 'Bend it like Beckham' [film]. Girls were brought up very differently in the West Indies, so my parents couldn't understand why.

Through a contextual analysis of Claire's experiences, she demonstrates the relationship between the different and the most salient axes of oppression, in this case, race and gender and the impact on her and her relations with others (Flintoff, Fitzgerald \& Scraton, 2008). Such accounts remind us that relations such as gender and race are connected and mutually constituted. Therefore, there is a need for a more developed understanding of the professional and personal experiences of women as coaches and how these are culturally variable (Glenn, 1999; Hall, 1996).

Although women are greatly more involved in the public sphere of $21^{\text {st }}$ century society and do often work in a full-time career combined with family responsibilities, this does not 'liberate' women nor necessarily automatically put women in a position to challenge cultural perceptions of what is expected of them. For the participants, despite being 'success stories' as women who have climbed to the top of their career ladder, a shared feeling was of guilt for what they perceive as ignoring the expectations of being a woman. This was the case for Anne when I asked her whether she had experienced any obstacles in her coaching career:

That shift hasn't really come... It is a guilt complex for where your time should be spent, if you feel you are neglecting your children, your family in any way, the guilt 
complex comes in. You've got to weigh up what you're doing and maybe you cut back on what you like doing. So you've got to cut corners to keep everything on an even keel and to keep yourself sane and not feel like you're doing the wrong thing.

This guilt complex was also shared by Helen who has to travel abroad many times over the course of the season with her team:

It is far more difficult for a woman to achieve in high performance coaching than it is for a man... I know there are members of my family that find it appalling I would think of leaving my husband and the children to go a Commonwealth Games in Melbourne. I have found that difficult and I have beaten myself up about that... I think it's a barrier I have put for myself, feeling guilty about going off and leaving the family.

These participants felt a guilt burden through, what they felt was neglecting their role as wife and mother. Paradoxically, for the participants without children and / or partner, they were made to feel 'abnormal'. Fiona alluded to being labelled as a lesbian because she does not have a 'traditional' family unit at home and was thus looked upon as failing to conform:

The assistant coach to the women's... She is part of that breed, you know, she's single, not married, that breed that's not 'normal'. I'm not 'normal' because I don't have a family; I have no kids so consequently I'm unusual.

For another coach of a different sport, she too felt out of place because she did not conform to the image of the dependent, domesticated woman. Sarah, who had 
previously played and captained the national women's team in her sport leading them to a World Cup final, is now the most qualified woman coach in her sport worldwide. She has extensive high performance coaching experience with a number of national teams including England. She self identifies as heterosexual but does not have a partner or children. Like Fiona, she too has experienced negative stereotyping and homophobia within her sport that is male dominated:

Yes, automatically everybody jumps to the conclusion that you're a lesbian... [it's like] "oh you're not married"? ... For goodness sake, how many men have to answer these questions and they don't. That's one of the biggest issues is the sexuality one.

Burton-Nelson (1994) writes that the culture of sport teaches men to talk about and consider women and their abilities with derision. Steinem (1992) also asserts that patriarchal cultures prefer women to be weak. However, a woman who reaches the senior levels of coaching poses a challenge to the male certainties that rest upon the powerful levels of sports leadership (Disch \& Kane, 2000). This intrusion is also often unsettling for the women coaches also (Disch \& Kane, 2000). These findings contribute to our understanding as to what the reaction is of those women coaches to a sense of resistance. That is, to feel unconfident, unmotivated, experience a guilt complex or feel outside of the cultural norms.

\section{Discussion and Conclusion}

This study reveals some of the responses from women coaches to the cultural expectations of femininity and the socially accepted role of being a woman. What emerges from the research are women's feelings of low self-confidence and 
reluctance to advance themselves, as well as bearing a burden of guilt when they do. The participants are all national, senior head coaches but describe feelings of culpability for pursuing their journey to the top of the coaching ladder. Women coaches' emotional struggles within a culture that is centred upon reasserting and maintaining male power and privilege (Kidd, 1990) contributes to our realisation of how such hegemony is "won rather than given" (Dewar, 1991, p. 20). The oppression of women in sport, as the theory of hegemony informs us, is not achieved through overt forms of discrimination but rather more subtle, insidious power relations (Halford \& Leonard, 2001). In the face of such collective acts of resistance, the masculine domination of coaching effects a form of individual, emotional struggle on women for daring to step out of the kitchen onto the court.

My exploration of women coaches' reactions to feeling out of place in their profession also reveals that women may self-select themselves out of working towards more senior roles. Importantly, I do not argue that women are naturally less confident or motivated than men coaches as some previous psychological studies have speculated. Whilst confidence and motivation to coach has been previously forwarded as an argument for women's underrepresentation, such studies lack a socio-cultural context, often conducted from a psychological perspective. Research has documented behavioural differences in males and females, or related women's low coaching confidence and intent to a lack of opportunities (e.g. Cunningham et al, 2003; Cunningham \& Sagas, 2003; Cunningham et al, 2007; Stangl \& Kane, 1991; Weiss et al, 1991; Weiss \& Stevens, 1993). However, to stop the argument there, does not suggest a particularly intellectually rigorous conception of the complexity of the cultural and historical issues that surround women coaches (Birrell, 1988). This study has explored some of the responses to the masculine hegemony of sport, 
documenting the participants' sense of self-confidence that they carried into their coaching career while witnessing other women often unwilling to aim towards high performance coaching positions. However, rather than 'blame' women for their under-representation, I contextualise their depleted confidence within the sociocultural environment in which they work and live. This adds to previous research that has reported the challenges that women coaches contend with, such as Kilty's (2006) work. She reported that women suffer from several 'internal barriers' (Kilty, 2006, p. 226). Namely that, women coaches had difficulty in identifying individual achievements and were unable to describe their personal strengths. My criticism of these 'internal barriers' is that Kilty (2006) depicts these as faults of the women through failing to locate or relate these within the culture of sport and society. Instead, Kilty (2006, p. 226) labels such barriers as 'perfectionism' and 'inhibitions'. In reference to women coaches displaying a lack of desire to coach at an elite level, Everhart and Chelladurai (1998) found that the desire to coach in both men and women decreased with an increase in coaching commitment. However, because the participants were athletes and not actual coaches, such results could be described as speculative and hypothetical. Additionally, such quantitative investigations fail to delve into the meanings ascribed to coaching for men and women, treating their experiences of coaching and sport as equal.

Just as earlier research found, my study updates this work in documenting women coaches' lack of self-belief in their capability to lead. West and Brackenridge in as early as 1990 stated that women are less confident than their male colleagues in adopting leadership roles. Prior to this, studies by Acosta and Carpenter (1985), Hart et al (1986) and Pease and Drabelle (1988) all concluded that many women do not aspire to apply for coaching positions. What the present study contributes is why 
women feel less self-efficacious and less driven to undergo coaching development and why women, who are already in the coaching system, prefer to remain in lower levels. The research also adds to our understanding of how engaging in resistance often affects the individual. Through their historical and social exclusion from such positions and due to the success of hegemony within sport, developing women coaches tend to have extremely low self-confidence. Often they are burdened by a guilt complex resulting from social and cultural constraints and expectations that indoctrinate them that their role in society is primarily a domestic, maternal one. For the women without family responsibilities, they experienced homophobia or were made to feel deviant. In this way, women in leadership positions are in a 'no-win' situation. This problematises the distributive approach to this focus of inquiry that occupies itself with descriptions of and readdressing unequal sporting opportunities (Dewar, 1991). If the opportunities do ever become equal for men and women and coaching becomes a meritocracy, women may be hesitant to step forward. In this way, I agree with Griffiths' (1995) description of self-esteem as a political concept, stating that individuals will construct their self-confidence upon their own patterns of and reactions to their history of exclusion and inclusion. The findings of the present study have revealed factors that have contributed to women's exclusion from the coaching profession and the impact of this exclusion. Griffiths argues that such experiences are affected by gender, which is then mediated by race, class and sexuality. For example, this study has provided some evidence of the connection between gender and race within the lives of the participants and the effect on their sporting participation. In the instance of coaching and in the case of my research, for men, patterns of exclusion or inclusion become, according to Griffiths, "self-fulfilling" and increases their self-confidence because men are the creators of and 'included' 
into such cultures as the elite levels of coaching (1990, p. 121). Self-esteem is therefore for the "masters": the culturally dominant group (Griffiths, 1995, p. 121).

The masculinist culture of sport is isolating for many women coaches; the consequence of such is erosion of their motivation and self-assurance. This implies that sport needs to create an environment that values women coaches and makes them feel 'included' and wanted. A consequence of this is that it may enhance women's sense of self-efficacy and positively influence their desire to pursue higher levels within the profession. The participants themselves represent leaks to the male hegemony of coaching in that they have reached the peaks of the profession and have great confidence in their ability to lead, however for some, they have had to bear the burden of guilt or the label of 'abnormality'. To begin with, it is up to sporting governing bodies to recognise men and women have different coaching experiences and thus, to treat coaches as a homogenous group in a male privileged culture is to ultimately alienate women. This is because, as Scott (1998, p. 44) argues, to pursue such equality could also be defined as "deliberate indifference". In this way, gender-blindness in relation to understanding coaching experiences is dangerous for how it ignores the ways in which gender shapes individual lives (Halford \& Leonard, 2001). Research should be direct at extracting the multiple cultural meanings, experiences and implications of what it means to a woman coach and the differences between women (and men). Within this, as I have briefly discussed earlier in this paper, a greater theorisation and appreciation of 'difference' through researching intersectionality is needed. Rather than researching simple characteristics held by different groups as much of the categorical research has done, we need to understand that women may have different experiences because of relations of power and how these are then experienced as inequalities (Flintoff et 
al, 2008). Furthermore, women's engagement in individual acts of resistance, such as the participants in this study, should be collected rather than solely examining episodic patterns of discrimination (Halford \& Leonard, 2001). This, of course, cannot be solely accomplished through interviews (Scraton et al, 1999). Moreover, a greater dissection of women's identities is needed to understand how some women's burden of guilt and / or crisis of confidence are a conjuncture of intersecting relations of power, such as race and sexuality, not just gender. This is for a re-construction of gender ideologies so that girls and women are able to invest time in their sport and coaching without feeling as if they are sporting intruders.

\section{References}

Acosta, R.V., \& Carpenter, L.J. (1985) Status of women in athletics - changes and causes. Journal of Physical Education, Recreation and Dance, 56 (6), 35 37.

Acosta, R.V., \& Carpenter, L.J. (2012). Women in Intercollegiate Sport: A Longitudinal, National Study Thirty-Five Year Update 1922 - 2012. Unpublished manuscript. Retrieved February $13^{\text {th }}, 2012$, from www.acostacarpenter.org.

Bachrach, P., \& Baratz, M. (1963) Decisions and nondecisions: An analytical framework. American Political Science Review, 57, 641 - 651.

Bennett, T. (2006) Popular culture and the turn to Gramsci. In J. Storey (ed.), Cultural theory and popular culture: A reader ( $3^{\text {rd }}$ edn., pp. 217-224). USA: Prentice Hall.

Birrell, S. (1988) Discourses on the gender/sport relationship: From women in sport to gender relations. In K. Pandolf (Ed.), Exercise and sport sciences review, 16 (pp.459-502). New York: Macmillan Publishing Company.

Birrell, S., \& McDonald, M. (2000). Reading sport, articulating power lines. In S. Birrell \& M. McDonald (Eds.), Reading sport: Critical essays on power and representation (pp. 3 - 14). U.S.A: Northeastern University Press.

Brabeck, M. M., \& Ting, K. (2000) Feminist ethics: Lenses for examining ethical psychological practice. In M. Brabeck (Ed.), Practicing feminist ethics in psychology (pp 17 - 37). Washington: American Psychological Association 
Brackenridge, C.H. (2001). Spoilsport: Understanding and preventing sexual exploitation in sport. London, UK: Routledge.

Bryant, J.E., \& McElroy, M. (1997) Sociological dynamics of sport and exercise. Englewood: Morton Publishing Company.

Bryman, A. (2004). Social research methods (2 ${ }^{\text {nd }}$ ed.). Oxford: Oxford University Press.

Burton-Nelson, M. (1994) The stronger women get, the more men love football: Sexism and the American culture of sports. U.S.A: Harcourt Brace \& Company.

Cole, E.B., \& Coultrap - McQuin, S. (1992) Towards a feminist concept of moral life. In E.B. Cole \& S. Coultrap-McQuin (eds.), Explorations in Feminist Ethics: Theory \& Practice (pp.111 -116). Bloomington: Indiana University Press.

Connell, R. (1987) Gender and power: Society, the person and sexual politics. Cambridge: Polity.

Cunningham, G.B., Doherty, A.J. \& Gregg, M.J. (2007) Using social cognitive career theory to understand head coaching intentions among assistant coaches of women's teams. Sex Roles, 56, $365-372$.

Cunningham, G.B., \& Sagas, M. (2002). The differential effects of human capital for male and female division I basketball coaches. Research Quarterly for Exercise \& Sport, 73 (4), 489 - 495.

Cunningham, G.B., \& Sagas, M. (2003a) Treatment discrimination among assistant coaches of women's teams. Research Quarterly for Exercise and Sport, 74 (4), $455-466$.

Cunningham, G.B., \& Sagas, M. (2003b). Occupational turnover intent among assistant coaches of women's teams: The role of organisational work experiences. Sex Roles, 49 (3/4), $185-190$

Cunningham, G.B., Sagas, M., \& Ashley, F.B. (2003) Coaching self-efficacy, desire to become a head coach, and occupational turnover intent: Gender differences between NCAA assistant coaches of women's teams. International Journal of Sport Psychology, 34 (2), 125 - 137.

Dewar, A.M. (1991) Incorporation of resistance? Towards an analysis of women's responses to sexual oppression in sport. International Review for the Sociology of Sport, 26 (1), $15-22$.

Disch, L., \& Kane, M. J. (2000) When a looker is really a bitch: Lisa Olson, sport, and the heterosexual matrix. In S. Birrell \& M. McDonald (Eds.), Reading sport: Critical essays on power and representation (pp. 108 - 144). U.S.A: Northeastern University Press. 
Donohoe, H. (2004). Support women in sport. Recreation, 63 (2), pp $22-23$.

Everhart, C. B., \& Chelladurai, P. (1998) Gender differences in preferences for coaching as an occupation: The role of self-efficacy, valence, and perceived barriers. Research Quarterly for Exercise and Sport, 69 (2), 188 - 200.

Ferguson, K.E. (1995) Bureaucracy and Public Life: The femininization of the polity. In N. Tuana \& R. Tong (eds.), Feminism and Philosophy: Essential Readings in Theory, Reinterpretation and Application (pp. 374-290). Colorado: Westview Press.

Fielding-Lloyd, B., \& Mean, L. (2011). "I don't think I can catch it": Women, confidence and responsibility in football coach education. Soccer and Society, $12(3), 345-364$.

Flax, J. (1995) Political philosophy and the patriarchal unconscious: A psychoanalytic perspective on epistemology and metaphysics. In N. Tuana \& R. Tong (eds.), Feminism and Philosophy: Essential Readings in Theory, Reinterpretation and Application (pp. 217 - 237). Colorado: Westview Press.

Flintoff, A., Fitzgerald, H., \& Scraton, S. (2008). The Challenges of Intersectionality: Researching difference in Physical Education. International Studies in Sociology of Education, 18 (2), 73-85.

Frye, M. (1983) The politics of reality: Essays in feminist theory. New York: Crossing Press.

Glaser, B.G. \& Strauss, A.L. (1967) The discovery of grounded theory. Chicago, IL: Aldine.

Glenn, Evelyn N. 1999. The Social Construction and Institutionalization of Gender and Race: An Integrative Framework. In M.M. Ferree, J. Lorber \& B.B. Hess (eds.), Revisioning Gender (pp. 3-43). New York: Sage.

Griffiths, M. (1995) Feminisms and the self: The web of identity. London: Routledge.

Halford, S., \& Leonard, P. (2001) Gender, power and organisations. Basingstoke: Palgrave.

Hall, A.M. (1996) Feminism and sporting bodies. Champaign, IL: Human Kinetics.

Hargreaves, J. (1993) Gender on the sports agenda. In A.G. Ingham \& J.W. Loy (Eds.), Sport in social development: Traditions, transitions and transformations (pp. 167 - 185). Champaign: Human Kinetics.

Hart, B., Hasbrook, C., \& Mathes, S. (1986) An examination of the reduction in the number of female interscholastic coaches. Research Quarterly for Exercise and Sport, 61, $259-267$. 
Hasbrook, C.A., Hart, B.A., Mathes, S.A., \& True, S. (1990). Sex bias and the validity of believed differences between male and female interscholastic athletic coaches. Research Quarterly for Exercise and Sport, 61 (3), 259 - 267.

Kamphoff, C., Armentrout, S.M., \& Driska, A. (2010). The token female: Women's experiences as Division 1 collegiate head coaches of men's teams. Journal of Intercollegiate Sport, 3, 297 - 315.

Kane, M.J., \& Stangl, J.M. (1991). Employment patterns of female coaches in men's athletics: Tokenism and marginalization as reflections of occupational sexsegregation. Journal of Sport \& Social Issues, 15 (1), $21-41$.

Kanter, R.M. (1977). Men and women of the corporation. New York: Basic Books.

Kasper, A.S. (1994). A feminist, qualitative methodology: A study of women with breast cancer. Qualitative Sociology, 17 (3), 263 - 281.

Kerr, G., \& Marshall, D. (2007) Shifting the culture: Implications for female coaches, Canadian Journal for Women in Coaching, 7 (4): 1 - 4.

Kidd, B. (1990) The men's cultural centre: Sports and the dynamic of women's oppression / men's repression. In M. Messner \& D. Sabo (eds.). Sport, men and the gender order: Critical feminist perspectives (pp. 31 - 44). Champaign, IL: Human Kinetics.

Kilty, K. (2006) Women in coaching. The Sports Psychologist , 20: $222-234$.

Knoppers, A. (1994). Gender and the coaching profession. In S. Birrell \& C.L. Cole. (Eds.), Women in sport and culture (pp 119 - 135). Champaign: Human Kinetics.

Lovett, D.J. \& Lowry, C.D. (1994). "Good old boys" and "Good old girls" clubs: Myth or reality? Journal for Sport Management, 8 (1), 27 - 35.

Lowry, C. D., \& Lovett, D. J. (1997). Women coaches: Does when dictate why they leave? Applied Research in Coaching and Athletics Annual, 12, 35-53.

Lyle, J. (2002). Sports coaching concepts: A framework for coaches' behaviour. London: Routledge.

Mac an Ghaill, M., \& Haywood, C. (2007) Gender, culture and society: Contemporary femininities and masculinities. UK: Palgrave MacMillan.

Manley, A., Greenlees, I, Thelwell, R., \& Smith, M. (2010). Athletes' use of reputation and gender information when forming initial expectancies of coaches. International Journal of Sports Science \& Coaching, 5 (4), 517 - 533.

Mason, J. (1996). Qualitative researching. London: Sage Publications.

Mathes, S.A. (1982). Women coaches: Endangered species? Paper presented at AAHPERD Convention, Houston. 
McDonald, M., \& Birrell, S. (1999) Reading sport critically: A methodology for interrogating power. Sociology of Sport Journal, 16, $283-300$.

Messner, M. (2002) Taking the field: women, men and sports. Minneapolis: University of Minnesota Press.

Miner, M.J. (1993) Women in sport - a reflection of the greater society? Journal of Physical Education, Recreation and Dance, 64 (3), $44-48$.

Norman, L. (2008) The UK coaching system is failing women coaches. International Journal of Sports Science and Coaching, 3(4), 447-464.

Olesen, V.L. (2000) Feminisms and qualitative research at and into the Millennium. In N.K. Denzin \& Y.S. Lincoln (Eds.), Handbook of qualitative research $\left(2^{\text {nd }}\right.$ ed., pp. 215 - 257). California: Sage Publications.

Parks, J., Russell, R., Wood, P., Robertson, M., \& Shewokis, P. (1995). The paradox of the contented working woman in intercollegiate athletics administration. Research Quarterly for Exercise and Sport, 66 (1), 73-79.

Pastore, D. L., Inglis, S., \& Danylchuk, K. E. (1996). Retention factors in coaching and athletic management: Differences by gender, position, and geographic location. Journal of Sport and Social Issues, 20 (4), 427-441

Pease, D., \& Drabelle, J. (1988) Pre-entry coaching expectations of women and men. Journal of Physical Education, Recreation and Dance, 59 (4), 30 - 32.

Reinharz, S. (1983) Experiential analysis: A contribution to feminist research. In G. Bowles \& R.D. Klein (Eds.), Theories of women's studies (pp. 162 - 191). London: Routledge and Kegan Paul.

Rindfleish, J., \& Sheridan, A. (2003). No change from within: Senior women managers' response to gendered organisational structures. Women in Management Review, 18 (6), 299 - 310.

Scraton, S., Fasting, K., Pfister, G., \& Bunuel, A. (1999) It's still a man's game? The experiences of top-level European women footballers. International Review for the Sociology of Sport, 34 (2), $99-111$.

Shaw, S., \& Slack, T. (2002). 'It's been like that for donkey's years': The construction of gender relations and the cultures of sports organizations. Culture, Sport, Society, 5 (1), 86 - 106.

Sports Coach UK. (2007) Sports coaching in the UK II. Leeds: Sports Coach UK.

Sports Coach UK. (2011). Sports coaching in the UK III. Leeds: Sports Coach UK.

Sports Coach UK. (2008) The UK coaching framework: An executive summary. Leeds: Sports Coach UK. 
Stangl, J.M., \& Kane, M.J. (1991) Structural variables that offer explanatory power for the under-representation of women coaches since Title IX: The case of homologous reproduction. Sociology of Sport Journal, 8, 47 - 60 .

Stanley, L., \& Wise, S. (Eds.) (1993) Breaking out again: Feminist ontology and epistemology ( $2^{\text {nd }}$ ed.). London: Routledge. .

Steinem, G. (1992) Revolution from within. Boston: Little, Brown and Company.

Stumph, K.J., \& Sagas, M. (2005). Gender disparities in career outcomes of assistant coaches: Discrimination or capital deficiencies? Applied Research in Coaching \& Athletics Annual, 20, $94-118$.

Theberge, N. (1993). The construction of gender in sport: Women, coaching, and the naturalization of difference. Social Problems, 40 (3), $301-313$.

Weiss, M.R., Barber, H., Sisley, B.L., \& Ebbeck, V. (1991) Developing Competence and confidence in novice female coaches II: Perceptions of ability and affective experiences following a season-long coaching internship. Journal of Sport and Exercise Psychology, 13, 336 - 363.

Weiss, M.R., \& Stevens, C. (1993) Motivation and attrition of female coaches: An application of social exchange theory. The Sport Psychologist, 7, 244-261.

West, A., \& Brackenridge, C. (1990) Wot! No women coaches?!: A report on the issues relating to women's lives as sports coaches in the United Kingdom 1989/90. Sheffield City Polytechnic: PAVIC Publications. 